\title{
Helicobacter pylori Virulent Genes in the Upregulation of CCL20 and $\beta$ - actin Expression and Progression towards Gastric Disorders
}

\author{
Radhakrishnan Selvi ${ }^{1}$, Perumal Venkatachalam ${ }^{1}$, Arcot Rekha $^{2}$, K. Dharaniya ${ }^{3}$, S. Ayesha ${ }^{3}$, R. Selvaraj ${ }^{4}$, \\ Shanthi Vijayaraghavan ${ }^{5}$ \\ ${ }^{1}$ Department of Human Genetics, Sri Ramachandra Institute of Higher Education and Research, Chennai, India \\ ${ }^{2}$ Department of Surgery, Saveetha Medical College, Saveetha University, Chennai, India \\ ${ }^{3}$ Department of Biomedical Sciences, Sri Ramachandra Institute of Higher Education and Research, Chennai-India \\ ${ }^{4}$ R. Selvaraj, Centre for Laboratory Animal Technology \& Research, Sathyabama University, Chennai, India \\ ${ }^{5}$ Department of Gastroenterology, Sri Ramachandra Institute of Higher Education and Research, Chennai, India
}

\begin{abstract}
Objectives: Helicobacter pylori, infection carryout a substantial role in the pathogenesis of gastric disorders. The pathogenic effect is shown to be associated with host bacterial interplay and $\operatorname{Vac} A$ and $C a g$ are recognized as imperative virulence determinants. A variety of carcinogenic pathways are triggered by $H$. pylori and CCL20 and $\beta$ actin are responsible for cellular progress and upregulation of these genes leads to metaplasia, dysplasia and gastric adenocarcinoma. Therefore, it is of interest to investigate the association of $\mathrm{Cag} A, \mathrm{Vac} A$ in the upregulation of $C C L 20$ and $\beta$-actin expression and progression towards gastric disorders.
\end{abstract}

Methods: Blood and gastric biopsy samples of chronic gastritis subjects $(n=100)$ were collected to identify the incidence of $H$. pylori by ELISA and Rapid urease test. The samples positive for both RUT and ELISA were subjected to RT-PCR for expression studies.

Results: Among the study subjects, $36 \%$ and $58 \%$ showed positive result for RUT and ELISA of which $29 \%$ $(p=0.0005)$ showed positive result for both RUT and ELISA. For expression studies, $48 \%$ and $90 \%$ showed higher significant $(p=0.0005)$ expression levels of Cag $A$ and Vac $A$ m2. $10 \%(p=0.023)$ showed a significant expression levels of $\operatorname{Vac} A \mathrm{~m} 1$ region. Likewise $31 \%$ and $90 \%(\mathrm{p}=0.0005)$ of patients showed higher significant expression levels of $C C L 20$ and $\beta$-actin.

Conclusion: Thus obtained results illustrated that $H$. pylori excites the production of Cag A, Vac A, CCL20 and $\beta$ actin and expression of these factors signify a promising biomarker in the early diagnosis of the infection and in analyzing the progression towards gastric disorders. J Microbiol Infect Dis 2019; 9(3):116-124.

Keywords: Helicobacter pylori, CCL20, $\beta$-actin, RT-PCR, gastric disorders

\section{INTRODUCTION}

Helicobacter pylori, a microaerophilic gramnegative bacilli, inhabits in mucus lining of gastric epithelium of the stomach. Human beings are the bacterium's solitary host and majority of people harboring $H$. pylori are asymptomatic [1]. Even though in most infected people $H$. pylori do not cause illness, it is the leading driving force of chronic gastritis and infectivity with this organism is the chief etiological component in the pathogenesis of gastrointestinal disorders [2]. H. pylori infections primarily bring on chronic superficial gastritis, which can advances all the way through chronic atrophic gastritis, intestinal metaplasia, and dysplasia towards gastric carcinoma [3]. On the other hand, progression emerges in only few patients and it relies upon various factors, together with bacterial and host genetic makeup $[4,5]$. $H$. pylori virulence factors, for instance cytotoxin-associated antigen A ( Cag A), along with vacuolating cytotoxin $(\operatorname{Vac} A)$ do liable for majority of these events. One potential interpretation is that patients with severe gastroduodenal lesions are infected by virulent strains of $H$. pylori, while subjects with moderate

Correspondence: Dr. R. Selvi, Department of Human Genetics, Faculty of Biomedical Sciences, Technology and Research, Sri Ramachandra Institute of Higher Education and Research, Porur, Chennai, India 
gastritis without ulcer/cancer are infected by the organisms with low pathogenic potential [6].

H. pylori strains comprising Cag $A$ are linked with enhanced threat in the evolution of atrophic gastritis and also gastric adenocarcinoma [7]. $H$. pylori pathogenesis firmly count on pathogenic determinants, such as $\operatorname{Vac} A$ that infuses the oncoprotein $\operatorname{Cag} A$ into the host cell. Cag $A$ persuades transformation of cell morphology inside the host cell that is linked with improved cell migration. Therefore, Cag $A$ interrupts normal cell and deliberates the carcinogenic potential which is demanding for the pathogenesis of $H$. pylori infection. Furthermore Cag $A$ interrelates with $\operatorname{Vac} A$, an added most important virulence factor for $H$. pylori, which bring about cellular vacuolization, and hinders cell proliferation and ulcer healing [8].

An autonomous $H$. pylori loci associated with greater disease threat is vacuolating cytotoxin that encrypts the secreted toxin $\operatorname{Vac} A$. The $V a c$ $A$ restrains $\mathrm{T}$-cell responses towards $H$. pylori that possibly will commit to prolonged existence of infection. Vac $A$ put forth multiple impacts on epithelial cell structure which bring about interruption in the function of gastric epithelial barrier and also intonation of inflammatory reaction. Further consequences of $\mathrm{Vac} A$ encompass interruption of late endosomal compartments that result in invitro vacuole formation [9]. $H$. pylori precise strain components are not perfect virulence agent, since majority of individuals inhabited with disease-linked strains persist asymptomatic and that has focused the demand to detect the host factors that control the pathological effects. Host mechanisms that are related to neoplastic conversion comprise improved cell turnover, injure to gastric mucosal layer by reactive oxygen metabolites and decline in the concentration of ascorbic acid in the gastric juice. In general it is established that for the breakthrough of oncogenesis, persistent inflammation persuaded through $H$. pylori is significant. A range of carcinogenic pathways are stimulated via $H$. pylori or else through its virulence components inside the host cell especially $\operatorname{Cag} A$, Vac $A$, which deliberate the epithelial cell oncogenic potential and thus they are at present the goal of broad investigation [10].
H. pylori infection which increases the tumor invasiveness and metastasis is normally found to be a threat for the progression towards gastric cancer. CCL20 is one of the chemokine that magnetizes immature dendritic cells along with memory $T$ cells and may perform a significant function in gastric inflammation. The ability of CCL20 to employ immature dendritic cells as well as $\mathrm{T}$ cells with these characteristics made to explore the expression of CCL2O in H. pyloriinduced chronic gastritis [11]. Earlier studies revealed that in swollen gastric tissue the expression of CCL20 is elevated and CCL20 may exhibit an important function in lymphocyte trafficking which is chemokine mediated in the event of gastric inflammation in Helicobacter infection [12].

$\beta$-actin, an essential component of the cytoskeleton and it is a housekeeping gene. It articulates in most of the eukaryotic cells, moreover implicated in organizing major housekeeping objectives. In addition it performs a significant function in regulation of transcription, chromatin remodeling, transport and processing of mRNA. In laboratory techniques to standardize protein and gene expressions $\beta$-actin is the frequently used endogenous reference controls as it is considered to have stable levels of expression in diverse physiological, cellular and experimental conditions. On the other hand, increasing data have revealed its differential expression in multiple cancers. In turn the knowledge about $\beta$ actin expression and dispersion in diverse cell types is not clear. Studies on $\beta$-actin expression in tissues will offer an enhanced comprehends of its function in carcinogenesis and it is used as a tumor biomarker because of its association with clinical pathological criteria. $\beta$-actin is also identified to be implicated in motility of cancer cells [13,14]. Dysregulation of oncogenic pathways with interruption of natural cell-cell communication results in the epithelial cell carcinogenic transformation. From the previous studies it is clear that gastric carcinomas involve Helicobacter pylori as primary carcinogen but the mechanisms by which $H$. pylori increases the risk of developing gastric cancer remain unclear. In the present study identification of host genetic determinant that inclined to the disease condition driven by $H$. pylori, provide insights to the carcinogenic mechanisms that 
contribute to the understanding of the pathogenesis and early diagnosis of gastric cancer.

Hence, investigation on host-bacterial interplay significantly broadens our perceptive regarding the pathophysiology of persistent inflammation and carcinogenesis. Recognition of $H$. pylori assisted cellular responses can afford peculiar and fair insight in the molecular method of $H$. pylori-dependent pathogenesis in vivo and may direct to newer therapeutic approach. To explore its prospective, a study was conducted to interrogate the expression levels of $\operatorname{Cag} A, \mathrm{Vac}$ $A, C C L 20$ and $\beta$-actin in subjects with chronic gastritis.

\section{METHODS}

The study was approved by the Institutional Ethics Committee of Sri Ramachandra Institute of Higher Education and Research (Deemed to be University) (year-2013). It is a prospective study and the study enrolled 100 chronic gastritis patients of both the sexes. Biopsy sample were collected through endoscopic procedures and simultaneously peripheral blood samples were also obtained from the Department of Gastroenterology at Sri Ramachandra Institute of Higher Education and Research (Deemed to be University). Subjects with chronic gastritis as well as positive for $H$. pylori infection were considered as case samples and the patients negative for $H$. pylori infection were considered as control samples, while subjects with co-morbid conditions besides chronic gastritis were excluded. A formalized informed consent form was acquired from the study subjects. The collected samples were employed for Rapid Urease Test (RUT) to identify the incidence of $H$. pylori and Enzymelinked immunosorbent assay (ELISA) to determine the $H$. pylori lgG antibody and Real time PCR (RT-PCR) to study the $\operatorname{Cag} A, \operatorname{Vac} A$, $C C L 20$ and $\beta$-actin expression levels. RT PCR was carried out by SYBR Green method and the expression levels were analyzed by comparative CT method.

\section{Identification of $\boldsymbol{H}$. pylori infection in gastric biopsy sample by RUT}

The RUT detects the existence of urease activity in the gastric biopsy samples for the determination of $H$. pylori infection. In brief, the hydration reagent was placed on top of the substrate pad, allowed to fully absorb and biopsy sample was positioned directly onto the reaction pad. Then the substrate pad was fold over onto the specimen and placed into the reaction chamber or pouch for an hour. The formation of the deep blue or purple color on the specimen within 60 minutes signifies that the specimen is infected with $H$. pylori (positive). Whereas, formation of a faint gray haze or pale blue on the specimen at 60 minutes is observed as a negative result [15]. The results were confirmed by running positive control along with test samples.

\section{Identification of $\boldsymbol{H}$. pylori $\lg G$ antibody in serum sample by ELISA}

The identification of IgG antibodies across $H$. pylori antigens was based on the use of sandwich-variant of solid-phase enzyme immunoassay. About $10 \mu$ l of positive, negative control (received along with the kit) and patient serum sample was added to the wells which bind to the antigen on the surface of the wells, the resulting complex is detected using conjugate- mouse monoclonal antibodies to human IgG with horseradish peroxidase (HRP). As a result, a "sandwich", bound to the plastic, containing peroxidase is formed and then incubated with tetramethylbenzidine substrate (TMB). Reaction of a substrate with the enzyme produces a colored product, thus indicating a positive reaction. The intensity of the color is directly proportional to the content of specific IgG antibodies to $H$. pylori antigen. Optical density was measured at a wavelength of 420 $\mathrm{nm}$ [16-18].

Positivity index (PI \%) of each sample was calculated using following formula

Positivity Index = Optical density of test sample / Cut off value

Where the cut off value $=$ Average of negative + 0.3

RT PCR analysis for the expression of $H$. pylori Cag A, Vac A, CCL20 and $\beta$-actin

Single step RNA isolation method with TRIzol reagent was employed to isolate the high quality RNA from tissue samples [19]. The gastric biopsy sample was homogenized with $1 \mathrm{ml}$ of TRIzol reagent to which $200 \mu$ of chloroform 
was added, incubated at room temperature $\left(25 \pm 1{ }^{0} \mathrm{C}\right)$ for 10 minutes and centrifuged at 10,000 rotations per minute (rpm) for 10 minutes. The upper aqueous phase was collected and to that $500 \mu \mathrm{l}$ of $100 \%$ ice cold ethanol was added to precipitate RNA and pelletized at the bottom after centrifugation. Discard the supernatant and re-suspend the pellet in $20 \mu \mathrm{l}$ of sterile Diethyl pyrocarbonate (DEPC) water and it was stored at $-80{ }^{\circ} \mathrm{C}$ until further use. Agarose gel electrophoresis was employed to determine the quality of the RNA; the quantification was achieved by Nanodrop. The quantity of the RNA on an average was found to be between1.8-2.0.

The qRT PCR analysis was accomplished by two step process; the isolated mRNA was transformed into cDNA using high capacity cDNA conversion kit followed by expression analysis. The primers for $\operatorname{Cag} A, \operatorname{Vac} A, C C L 20$ and $\beta$ - actin gene were acquired from the NCBI database. Gene sequence was downloaded in FASTA format and gene specific primers were designed. The following primers were used for Cag A, 5'- GATAACAGGCAAGCTTTTGAGG -3 (forward primer) 5 CTGCAAAAGATTGTTTGCGAGA-3 (reverse primer) and 5 - GGTCAAAATGCGGTCATGG -3 (forward $\quad$ primer) 5 CCATTGGTACCTGTAGAAAC - 3 (reverse primer) for $\operatorname{Vac} A \mathrm{~m} 1$ region and for $\operatorname{Vac} A \mathrm{~m} 2$ region 5 - GGAGCCCCAGGAAACATTG -3 (forward primer) 5'CATAACTAGCGCCTTGCAC -3 (reverse primer) and for CCL20 5 GCGCAAATCCAAAACAG -3' (forward primer) 5 - GTCCAGTGAGGCACAA -3 (reverse primer)were used and 5'AGAAAATCTGGCACCACACC -3 (forward primer) 5 - CCATCTCTTGCTCGAAGTCC-3 (reverse primer) for $\beta$-actin. The glyceraldehyde3-phosphate dehydrogenase (GAPDH) was employed as an exogenous control. Subsequently, the synthesized cDNA was employed for expression analysis using RT PCR by SYBR Green method. RT-PCR was performed in a $20 \mu \mathrm{l}$ reaction volume which contains $2 \mu \mathrm{l}$ of template (cDNA) $(50 \mathrm{ng} / \mu \mathrm{l}), 10 \mu \mathrm{l}$ of SYBR Green mix (2x), $1 \mu$ of forward and reverse primers $(5 \mathrm{pmol} / \mu \mathrm{l})$, and $7 \mu \mathrm{l}$ of DEPC water. Two sets of reactions were prepared for each sample, one with the desired primers and the other with the exogenous control GAPDH. PCR was performed for $10 \mathrm{~min}$ at $95^{\circ} \mathrm{C}$, pursued by 40 cycles at $95^{\circ} \mathrm{C}$ for $15 \mathrm{sec}$, at $50^{\circ} \mathrm{C}$ for 30 sec, $60^{\circ} \mathrm{C}$ for $30 \mathrm{sec}$ and final extension for 1 $\min$ at $60^{\circ} \mathrm{C}[20,21]$. The comparative threshold method (CT method) was adopted to quantify the expression level of the above said genes. In this method the RT PCR Ct values (cycle threshold) of the test sample was compared with a control sample (negative for $H$. pylori); $\mathrm{Ct}$ values of the sample of interest and the control were normalized to an appropriate endogenous housekeeping gene.

\section{Statistical analysis}

The collected data were examined with IBM.SPSS statistics software 23.0 Version. To illustrate data descriptive statistics frequency analysis, percentage analysis was employed for categorical variables and for continuous variables the mean and standard deviation were employed. Chi-Square test was used to find the significance in categorical data; similarly the Fisher's Exact was used if the expected cell frequency is less than 5 in $2 \times 2$ tables. The probability value $\leq 0.05$ is considered as significant in the above statistical tool.

\section{RESULTS}

\section{Demographic details of the study subjects}

Gastric biopsy samples and blood samples $(n=100)$ were collected from the study subjects. Among the study subjects, $86 \%$ were males and the remaining $14 \%$ were females. The age ranges between 23 to 63 years with a mean of $42.5 \pm 11.9$ years.

\section{Identification of $\boldsymbol{H}$. pylori infection in gastric biopsy sample by RUT}

RUT identifies the existence of urease activity in the gastric biopsy samples for the determination of $H$. pylori infection. The formation of the deep blue or purple color on the specimen signifies the $H$. pylori infection. Out of 100 subjects, 36\% of patients showed positive for infection with $H$. pylori and rest of the patients showed a negative result.

\section{Identification of $\boldsymbol{H}$. pylori IgG antibody in serum sample by ELISA}

Presence of $H$. pylori in the serum sample was measured by sandwich ELISA. Reaction of a 
substrate with the enzyme produces a colored product, (Figure 1) thus indicating a positive reaction. The intensity of the color is directly proportional to the content of specific $\lg G$ antibodies to $H$. pylori antigen. Among the study subjects, $58 \%$ showed positive result signifying the incidence of $H$. pylori lgG antibody.

Identification of $\boldsymbol{H}$. pylori infection in gastric biopsy and blood samples

About $29 \%(p=0.0005)$ of samples showed a positive result both by RUT and ELISA, signifying the existence of $H$. pylori infection.
RT PCR analysis for the expression of $H$. pylori Cag A, Vac A, CCL20 and $\beta$-actin

The samples which showed positive result for RUT and ELISA were subjected to RT PCR to study the expression levels of $\operatorname{Cag} A, \operatorname{Vac} A$ and host genetic factors (CCL2O and $\beta$-actin). The 2$\triangle \triangle \mathrm{CT}$ value of $H$. pylori virulent genes and host genetic factors was calculated and the expression levels are given in Figures 2 and 3.

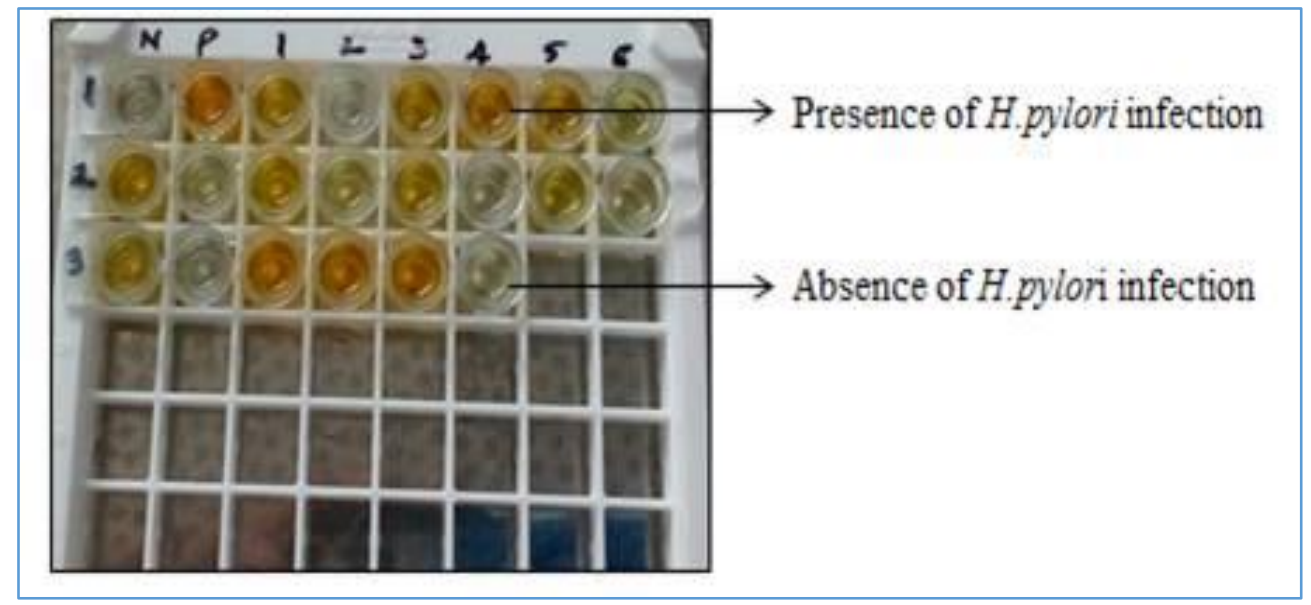

Figure 1. ELISA test showing the presence and absence of $H$. pylori infection in serum sample.

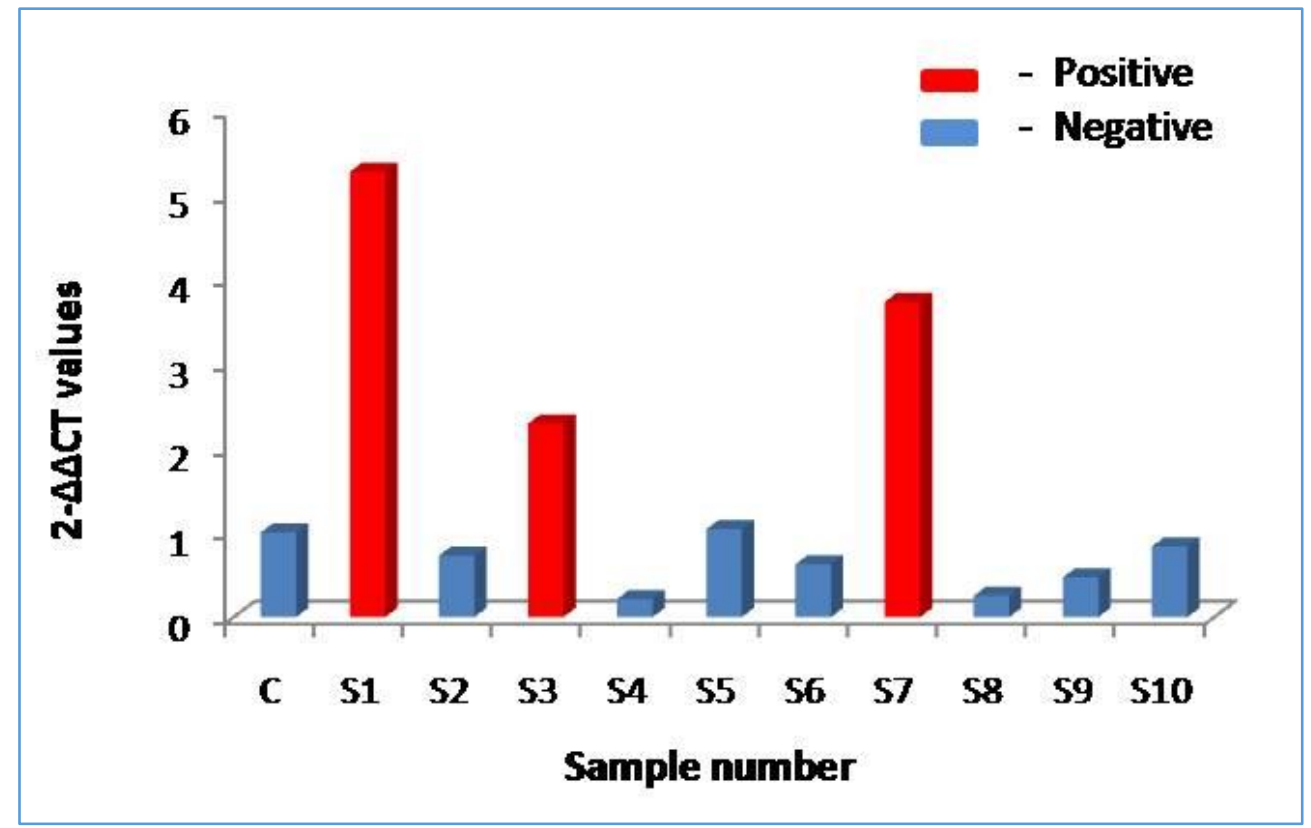

Figure 2. The 2- $\triangle \Delta C T$ values of $C C L 20$ expression from the gastric biopsy sample of the study subjects. 


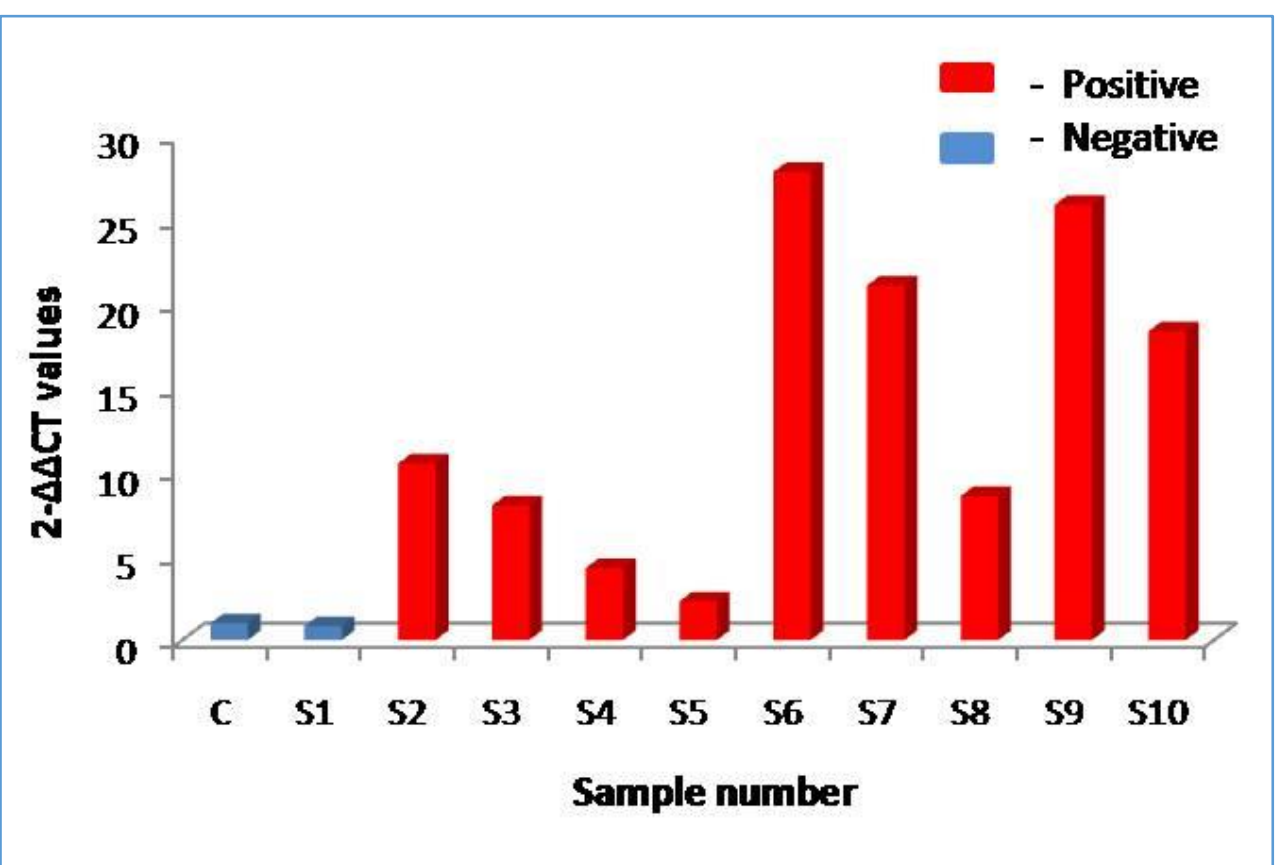

Figure 3. The 2- $\Delta \Delta C T$ values of $\beta$-actin expression from the gastric biopsy sample of the study subjects

The RT PCR analysis for the expression of $H$. pylori virulent genes reveals that among the study subjects $48 \%$ and $90 \%$ showed higher significant $(\mathrm{p}=0.0005)$ expression levels of Cag $A$ and $\operatorname{Vac} A \mathrm{~m} 2$. Whereas, $10 \% \quad(\mathrm{p}=0.023)$ showed a significant expression levels of $\operatorname{Vac} A$ $\mathrm{m} 1$ region. While $31 \%$ and $90 \%(\mathrm{p}=0.0005)$ of patients showed higher significant expression levels of CCL2O and $\beta$-actin respectively. An association analysis was performed between the $H$. pylori virulent genes and host gene expression levels, in which the association analysis between Cag A, Vac A m2 and CCL20, $\beta$-actin showed a higher significant expression levels $(p=0.0005)$, that signifies a strong association towards disease progression and Vac $A \mathrm{~m} 1$ did not show any significant result $(p=1.000)$ which indicates a weak association towards gastric disorders.

\section{DISCUSSION}

$H$. pylori are identified as the governing organism of human gastric environment and its existence leads to constant inflammatory response and alter host cell signaling pathways. Therefore, in the pathogenesis of gastric disorders, the chronic infection caused by $H$. pylori is an eminent risk determinant for chronic gastritis and peptic ulcer [22].
Virulence factors articulated by most of the $H$. pylori strains have emerged to alter host cell signaling pathways. Long-standing bearer of the organism extensively enhances the threat of establishing site-precise diseases [23]. In accordance with the clinical importance of $H$. pylori a study was performed to determine the role of virulent genes ( $\operatorname{Cag} A$ and $\operatorname{Vac} A$ ) in the upregulation of CCL2O and $\beta$-actin expression and progression towards gastric disorders in subjects with chronic gastritis. Out of 100 samples, $36 \%$ and $58 \%$ of patients showed positive result for RUT and ELISA respectively, signifying the existence of infection with $\mathrm{H}$. pylori and $29 \%$ showed positive for both the test and were subjected to RT-PCR for expression studies. It was determined that, Cag A, Vac $A$ $\mathrm{m} 2, \quad C C L 20$ and $\beta$-actin showed higher significant expression levels whereas, Vac A m1 showed a significant expression levels respectively. An association analysis was performed between the $H$. pylori virulent genes and host gene expression levels, which signifies a strong / moderate or weak association towards the progression of gastric disorders.

Among the individuals infected with $H$. pylori, the variations in gastric disease progression may be linked to variable host characteristics, disparity among $H$. pylori strains, precise interactions 
between host and microbial determinants and environmental influences. The antibodies to the Cag A protein is found in the sera of $100 \%$ of subjects infected with this bacterium who have peptic ulcer however merely 60 to $62 \%$ of patients who have gastritis [24-26]. As a result, the existence of $\mathrm{Cag} A$ is linked to infection with $H$. pylori to bring about peptic ulceration and it is a significant method to find out the Cag $A$ status of $H$. pylori in biopsy samples and are likely to be imperative.

The most essential virulence determinants formed by $H$. pylori is Vac $A$. Various studies revealed that $H$. pylori strains that encompass definite Vac $A$ types such as $\mathrm{s} 1, \mathrm{~m} 1$ are linked with an elevated risk of gastric intestinal disorders than s2 or m2 Vac $A$ types. In patients who are tested positive for $\operatorname{Vac} A$ but negative for $H$. pylori the threat for gastric cancer was greater when correlated with individuals who were tested positive for both. Studies on $H$. pylori have linked vacuolating cytotoxin with particular signal sequence ( $\mathrm{m} 1$ and $\mathrm{m} 2$ ) allele of the underlying $\operatorname{Vac} A$ gene to gastritis. Many recent studies have confirmed clinical and pathological disparity among strains holding diverse Vac A polymorphisms [27]. Studies on biological behavior and clinical organizations related to dissimilar Vac $A$ genotypes are essential for a profound knowledge of their role in disorders induced by $H$. pylori and for the evolution of new strategy to counteract their outcomes. In the present study, the Vac $A$ allele $\mathrm{m} 2$ region of $H$. pylori was found to be strongly linked with chronic gastritis than allele $\mathrm{m} 1$. Therefore these virulence factors of $H$. pylori can be employed as indicator to determine the risk of budding serious gastrointestinal disorders.

$\beta$-actin, a housekeeping gene, is expressed nearly in every eukaryotic cell and is implicated in managing basic housekeeping functions and it diversely expressed in multiple cancers. The over expression of $\beta$-actin, bring about modification of various signaling pathways. On the whole in gastritis, improved $\beta$-actin expression has been described, which modifies the cellular growth, distribution and proliferation. Knowledge on $\beta$-actin expression in biopsy sample will offer a enhanced comprehend of its function in carcinogenesis. Thus, it could possibly signify a potential biological marker in early identification and prognosis of gastric carcinoma. A study by $\mathrm{Xu} \mathrm{J}$ et al, illustrated that $\beta$-actin level was extensively higher in gastric cancer tissues and the correlation between $\beta$ actin expression and the neighboring lymph node metastasis was statistically important, which explained that over expression of $\beta$-actin might be partly responsible to the local lymph node metastasis of gastric cancer. Thus $\beta$-actin was found to be the most conventional and dynamic protein and it is over expressed in gastric cancer tissues and may perhaps perform a vital role in metastasis of gastric cancer [28]. Similarly Shafqat A Khan et al, investigated the association of cell type precise $\beta$-actin expression in gastric carcinoma by means of clinicopathological specifications by RT-PCR and western blotting. Their study result revealed a significant over expression, equally at protein and mRNA level. The above studies imply the potentials of $\beta$-actin as a cancer biomarker and proposed as a promising target for chemotherapy [13]. In the current study expression of $\beta$-actin is upregulated in $90 \%$ of subjects with $H$. pylori persuaded gastritis.

A precise chemokine receptor for CCL2O is CCR6 which is particularly articulated on few memory T cells and dendritic cells. CCL2O has proved to preferably attract memory $T$ cells, and perform a significant task in gastric inflammation. In gastric mucosa, infection with $H$. pylori is correlated with an inflammatory reaction leading to persistent gastritis, peptic ulcers and gastric carcinoma. At the site of infection with $H$. pylori there is an improved T-cell infiltration. In the present study $31 \%$ of samples showed over expression of CCL2O and rest of the samples showed normal expression when compared to the control sample. Previous studies confirmed that in irritated gastritis tissue the CCL20 expression is elevated. The CCR6/CCL20 plays a vital part in the gut-associated lymphoid tissue homeostasis and also in the organization of mucosal immunity and increased expression of CCL2O has been noticed in gastrointestinal inflammation. CCL2O acts as a ligand for chemokine receptor CCR6 and Yi-Ying Wu et al examined the function of CCR6 and CCL20, in promoting an inflammatory reaction in the gastric epithelial cells during infection with $H$. pylori. The study result indicated that there was drastically improved CCR6 expression in the gastric mucosa. Their results proposed that the 
interplay between CCR6 and CCL20 might perform a critical function during gastric inflammation [12]. The over expression of CCL20 were certainly linked with the Helicobacter pylori colonization density. A study by Akira Yoshida et al to detect the protein and mRNA levels of CCL2O by RT-PCR and ELISA, revealed that the expression of CCL20 at protein and mRNA levels were considerably high in subjects positive for $H$. pylori and significantly declined following complete eradication. The correlation between CCL2O concentrations and the extent of chronic gastritis demonstrated that the CCL20 interplay may possibly be entailed in the evolution of gastritis induced by $H$. pylori [29].

In summary, the obtained study result proposed that Cag A, Vac A, CCL2O and $\beta$-actin might play significant role in categorizing the disease severity and knowledge on $H$. pylori virulence factors provide the clarification on disease pathogenesis. Moreover CCL20, $\beta$-actin and its associated signaling pathways perform substantial role in retaining the functions of gastric mucosa and dysregulation of these determinants contributes to gastric cancer initiation as well as progression. The limitations in the present study indicates that altered expression of host genetic factors is not found at a higher percentage as compared to cancerous tissues but comparatively found at a rational rate in chronic gastritis as it may be one of the reasons for its cause or may develop in time.

\section{Conclusion}

Infection with $H$. pylori excites the production of Cag $A, \operatorname{Vac} A, \quad C C L 20$ and $\beta$-actin and expression of these factors is upregulated in the gastric epithelium of subjects with gastritis induced by $\mathrm{H}$. pylori and may signify a promising biomarker in the early identification of infection with $H$. pylori and in analyzing the progression towards gastric disorders.

\section{ACKNOWLEDGMENTS}

The authors thank the subjects who participated in the current study and they extend their thanks to Dr. Solomon.F.D.Paul for his support and encouragement to carry out the research work.
Declaration of Conflicting Interests: The authors declare that they have no conflict of interest.

Funding: This project received no specific grant from any funding agency in the public, commercial, or not-for-profit sectors.

\section{REFERENCES}

1. Atherton JC. The pathogenesis of Helicobacter pylori induced gastro-duodenal diseases. Ann Review of Pathology 2006; 1:63-96.

2. Ito $\mathrm{Y}$, Azuma $\mathrm{T}$, Ito $\mathrm{S}$, et al. Analysis and typing of the Vac $A$ Gene from Cag A-Positive Strains of Helicobacter pylori isolated in Japan. J Clin Microbiol 1997; 35:1710-1714.

3. Correa P. Human gastric carcinogenesis: a multistep and multifactorial process-First American Cancer Society Award Lecture on Cancer Epidemiology and Prevention. Cancer Res 1992; 52:6735-6740.

4. Blaser MJ. Linking Helicobacter pylori to gastric cancer. Nature Medicine 2000;6:376-377.

5. Peek RM, Blaser MJ. Helicobacter pylori and gastrointestinal tract adenocarcinomas. Nature Rev Cancer 2002;2:28-37.

6. Ernst PB, Peura DA, Crowe SE. The translation of Helicobacter pylori basic research to patient care. Gastroenterology 2006;130:188-206.

7. Blaser MJ, Perez-Perez GI, Kleanthous $\mathrm{H}$, et al. Infection with Helicobacter pylori strains possessing Cag $A$ associated with an increased risk of developing adenocarcinoma of the stomach. Cancer Res 1995; 55:2111-2115.

8. Nagy TA, Frey MR, Yan F, Israel DA, Polk DB, Peek RM Jr. Helicobacter pylori regulates cellular migration and apoptosis by activation of phosphatidylinositol 3-kinase signaling. J Infect Dis 2009; 199:641-651.

9. Ogiwara $H$, Sugimoto $M$, Ohno $T$, et al. Role of deletion located between the intermediate and middle regions of the Helicobacter pylori Vac $A$ gene in cases of gastroduodenal diseases. J Clin Microbiol 2009; 47:3493-3500.

10. Noach LA, Bosma NB, Jansen J, Hoek FJ, Van Deventer SJ, Tytgat GN. Mucosal tumor necrosis factor-alpha, interleukin-1 beta, and interleukin-8 production in patients with Helicobacter pylori infection. Scand J Gastroenterol 1994; 29:425-429.

11. Liao F, Rabin RL, Smith CS, Sharma G, Nutman TB, Farber JM. CC-chemokine receptor 6 is expressed on diverse memory subsets of T cells and determines responsiveness to macrophage inflammatory protein 3a. J Immun 1999; 162:186-194.

12. Wu YY, Tsai HF, Lin WC, et al. Upregulation of CCL20 and Recruitment of CCR6+ Gastric Infiltrating 
Lymphocytes in Helicobacter pylori Gastritis. Infect Immun 2007; 75:4357-4363.

13. Khan SA, Tyagi M, Sharma AK, et al. Cell-type specificity of $\beta$-actin expression and its clinicopathological correlation in gastric adenocarcinoma. W J Gastroenterol 2014; 20:1220212211.

14. Xu J, Zhang Z, Chen J, Liu F, Bai L. Over expression of $\beta$-actin is closely associated with metastasis of gastric cancer. Hepatogastroenterology 2013; 60:620-623.

15. Elitsur Y, Hill I, Lichtman SN, Rosenberg AJ. Prospective Comparison of Rapid Urease Tests (PyloriTek, CLO Test) for the Diagnosis of Helicobacter pylori Infection in Symptomatic Children: A Pediatric Multicenter Study. Am J Gastroenterol 1998; 93:217-219.

16. Ping-I Hsu. Application of Serology in the Diagnosis of Helicobacter pylori Infection in Patients with Atrophic Gastritis. J Chine Med Associat 2010; 73:561-562.

17. Hung $\mathrm{HH}$, Chen TS, Lin HC. Immunoglobulin G Antibody against Helicobacter pylori is an accurate Test for atrophic gastritis. J Chine Med Associat 2010; 73:355-359.

18. Cutler AF, Prasad VM, Santogade P. Four-year trends in Helicobacter pylori IgG serology following successful eradication. Am J Med 1998; 105:18-20.

19. Chomczynski P, Sacchi N. Single-step method of RNA isolation by acid guanidinium thiocyanatephenol-chloroform extraction. Analytical Biochemistry 1987; 162:156-159.

20. Wang J, Wang WH, Li J, Liu FX. Celecoxib inhibits Helicobacter pylori colonization-related factors. World Journal of Gastroenterology 2010; 16:846-853.

21. He Q, Wang JP, Osato M, Lachman LB. RealTime Quantitative PCR for detection of Helicobacter pylori. J Clin Microbiol 2002; 40:3720-3728.

22. Peek RM Jr, Miller GG, Tham KT, et al. Detection of Helicobacter pylori Gene Expression in Human Gastric Mucosa. J Clin Microbiol 1995; 33:28-32.

23. Wroblewski LE, Peek RM Jr, Wilson KT. Helicobacter pylori and Gastric Cancer: Factors that Modulate Disease Risk. Clinal Microbiol Rev 2010; 23:713-739.

24. Covacci A, Censini S, Bugnoli $M$ et al. Molecular characterization of the $128-\mathrm{kDa}$ immune dominant antigen of Helicobacter pylori associated with cytotoxicity and duodenal ulcer. Proc Natl Acad Sci U S A; 1993; 90:5791-5795.

25. Cover TL, Dooley CP, Blaser MJ. Characterization and human serologic response to proteins in Helicobacter pylori broth culture supernatants with vacuolizing cytotoxin activity. Infect Immun 1990; 58:603-610.
26. Crabtree JE, Taylor JD, Wyatt JI, et al. Mucosal IgA recognition of Helicobacter pylori $120 \mathrm{kDa}$ protein, peptic ulceration, and gastric pathology. Lancet 1991; 338:332-335.

27. Foegeding NJ, Caston RR, McClain MS, Ohi MD, Cover TL. An overview of Helicobacter pylori Vac $A$ Toxin Biology. Toxins 2016; 8:173.

28. Xu J, Zhang Z, Chen J, Liu F, Bai L. Over expression of $\beta$-actin is closely associated with metastasis of gastric cancer. Hepatogastroenterology 2013; 60:620-623.

29. Yoshida $A$, Isomoto $H$, Hisatsune $J$ et al Enhanced expression of CCL20 in human Helicobacter pylori associated Gastritis. Clin Immun 2009; 130:290-297. 